were numerous small râles, dry and moist. A few of the same character were also obtained in the lateral and anterior regions. The patient was ordered two grains of antifebrin every four hours and light linseed-meal jacket-poultices. At 10 P.M. the patient was again visited. The swelling had increased in all the regions already mentioned, but the right anterior regions showed the greatest increase. The swelling in the neck was very considerable. Râles of the same nature as at the last examination were heard. The respirations were 52 per minute, the pulse was 120 , and the temperature was $99^{\circ}$. The patient looked greatly relieved. His skin was very moist and the diminished frequency of the respirations was specially evident. Examination of the mouth and throat was negative. The antifebrin was ordered to be continued as well as the poultices. On Dec. 4th the swelling was much the same as on the former day. Certainly it was not increased. The respirations were 42 per minute, the pulse was 110 , and the temperature was $99^{\circ}$. Râles were still present, but the moist ones were more numerous than the dry. On the 5th the swelling was less in the cheeks, neck, and anterior regions of the thoracic wall; the tension also was less all over. The respirations were 40 per minute, the pulse was 110, and the temperature was normal. The patient was hoarse when he spoke. There was nothing abnormal to be seen in the throat, nor was there any evidence of distress on breathing. The antifebrin was discontinued. On the 6 th the swelling on the face, neck, and anterior regions of the chest was distinctly less, although the posterior parts of the thoracic wall did not show so marked a diminution. The respirations were 30 per minute, the pulse was 100 , the temperature was normal, and the râles had disappeared. On the 7th the swelling was less all over the parts affected. The respirations were 26 per minute, the pulse was 86, and the temperature was normal. From this date the swelling gradually diminished till it had quite disappeared on the tenth day from its onset. The part which longest gave evidence of the swelling was the posterior region of the right thoracic wall.

The treatment consisted in two-grain doses of antifebrin every four hours till the temperature became normal and poultices of linseed-meal for the first three days. The chest was then rubbed morning and evening with hot animal oil (neatsfoot) and enveloped in cotton-wool.

As stated by Dr. J. R. Gibson in THE LANCET of Dec. 8 th, 1894, p. 1345, these cases are sufficiently rare to be worthy of record. In this case the efforts of coughing were so comparatively slight as to suggest the likelihood of a congenital weakness in some of the alveoli of the lungs. The father of the patient died from phthisis. The probability is that the ruptured air vesicles allowed of the escape of their contents into the cellular tissue between the lobules of the lung, giving rise to inter-lobular emphysema. Thence the air found its way to the root of the right lung and into the anterior mediastinum, and thence guided by the cervical fascir into the neck and face regions. The duration of time required to absorb the air was in this case ten days. The distress of the patient was confined to the first three days of the illness.

Aberdeen.

Whatern Counties Veterinary Association.At the meeting of the Western Counties Veterinary Association held at Exeter recently the President (Mr. W. Penhale) referred to the inequality in the treatment by the War Office of veterinary surgeons as compared with medical officers in regard to the advancement of their rank in yeomanry regi. ments and added that the veterinary surgeon had never stood out with such prominence and importance as he did to-day in matters relating to public health.

Diphtheria in South Wales.-At a recent meeting of the Penarth Health Committee Mr. R. F. Nell, the medical officer of bealth, reported that 57 cases of diphtheria had been notified during November. The committee decided to close all public elementary schools and Sunday schools until January next, and to request the Local Government Board to hold an inquiry and communicate with the district and county medical officers of health upon the matter.-At the meeting of the Pontypridd District Council held on Nov. 28th Mr. H. Davies, the medical officer of health, reported that 31 cases of diphtheria had been notified during the past two weeks.

\section{ollinical dotos:}

\section{MEDICAL, SURGICAL, OBSTETRICAL, AND} THERAPEUTICAL.

\section{A NOTE ON THE EXCISION OH JOINTS IN RHEUMATOID ARTHRITIS.}

By F. A. Southam, M.B. Oxon., F゙.R.C.S. ENG.,

SURGLON TO THE MAYCTESTER ROIAL TNFTRARY; LECTURER ON OPERATIVE SURGERY, OWLNS COLLEGE.

I HAVE read with much interest Dr. F. W. Collinson's case of excision of both elbow-joints for rheumatoid arthritis, ${ }^{1} \mathrm{Mr}$. Howard Marsh's two cases of excision of the knee-joint for osteo-arthritis, and the remarks of Dr. G. A. Bannatyne and Dr. R. D. Parker on the question of operative interference in rheumatoid arthritis, ${ }^{2}$ having myself some years ago performed six excisions of joints in three patients who were the subjects of this affection. In four instances excision of the knee was performed in order to correct a flexed and ankylosed position in which the limb. had become quite useless, and in two instances the elbow was excised with the object of substituting a moveable for a perfectly stiff joint.

On looking up the literature of the subject at the time the operations were performed, I remember, like Dr. Collinson, "being struck by the silence of authorities upon the subject of excision," and I therefore briefly record the following. cases in the hope that an account of the results obtained may prove of some assistance to others desiring information upon this method of treatment, when the question of its employment for the relief of rheumatoid arthritis arises. It is interesting to note that all three patients were females, about thirty years of age, and that in each instance the wounds very readily healed. As regards the condition of the joints, the ends of the bones were more or less sclerosed and eburnated, and there was a formation of osteophytes around the articular surfaces, varying in extent in the different cases. Since the date of the last operation (December, 1894) I have not met with any other cases where excision has been indicated.

CASE 1.-The patient was a female, aged 29 years, in whom almost every joint was more or less ankylosed, the affection having commenced in the temporo-maxillary articulations about eight years previously. The knee-joints could not be extended beyond a right angle, and she had been confined to bed for seven years, being incapacitated from walking on account of the flexed condition of both legs. The right elbow was completely ankylosed at an angle of about 100 degrees. In 1893 both the knee-joints and the the right elbow-joint were excised with satisfactory results. In the lower extremities bony union with the limbs in the extended position was obtained, so that the patient from being completely bedridden was soon able to walk several miles and she continues to do so. Good movement was obtained in the elbow-joint and it is still present.

CASE 2. - In this patient, a female, aged 30 years, both the knee-joints were ankylosed and in exactly the same condition as were those of the last patient, as well as several of the other joints. The affection had commenced in the knees about seven years previously, and for about four years the patient had been unable to walk. She lived in the same neighbourhood as the subject of Case 1 and came to the hospital in consequence of having heard of the satisfactory results of the operation upon the knee-joints in that case. In 1894 , both knee-joints were excised with a similar result. the power of Jocomotion being restored to the patient.

CASE 3.-The patient was a female, aged 30 years, in whom almost all the joints were affected, but only to a slight extent, with the exception of the left elbow, which was completely ankylosed at an obtuse angle. In 1894 the left elbow was excised and a moveable joint was obtained. Good movement was present when the patient, who has been lost sight of, was last seen some months after the operation.

Manchester.

I The LanceT, Nov. 4th, 1899, p. 1230 2 The LANCET, Nov. 18th, 1899, pp. 1400 and 1401. 